PAPER

\title{
Neuropsychiatric porphyria in patients with refractory epilepsy: report of three cases
}

A S Winkler, T J Peters, R D C Elwes

See end of article for

authors' affiliations

J Neurol Neurosurg Psychiatry 2005;76:380-383. doi: 10.1136/jnnp.2003.033951

.....................

Correspondence to: Professor T J Peters, Dept of Clinical Biochemistry, King's College Hospital

Denmark Hill, London SE5 9RS, UK; timothy.peters@ kcl.ac.uk

Received 9 December 2003 In revised form

18 May 2004

Accepted 15 June 2004

\begin{abstract}
Objectives: Although epileptic seizures are an infrequent feature of acute attacks of the neuropsychiatric porphyrias, there are no significant reports of porphyria in chronic epilepsy. This paper attempts to redress the balance.
\end{abstract}

Methods: Three case reports, including detailed laboratory and molecular diagnostics.

Results: Two patients with variegate porphyria and one with acute intermittent porphyria, referred within 1 year to a specialist porphyria service, with a long history of chronic refractory epileptic seizures, are described.

Conclusions: Porphyria may be an aetiological factor in some cases of chronic refractory partial or generalised epilepsy. Porphyria should also be considered if addition of a new anti-epileptic medication causes a major deterioration in the epilepsy.
A cute symptomatic seizures are a well recognised feature of porphyria in relapse. ${ }^{12}$ It is less clear if porphyria can present with seizures or whether it should be considered in the differential diagnosis of cryptogenic, focal or generalised epilepsy. In the course of 1 year, three patients were referred to the Metabolic Clinic at King's College Hospital with epilepsy as a presenting symptom and were found to have one of the acute neuropsychiatric porphyrias. In all cases the use of inappropriate medication exacerbated the seizures and in at least two cases the porphyria may have been an aetiological factor in the chronic epilepsy.

\section{Case 1}

A 20 year old Yemeni female was referred to the Metabolic Clinic with an 8 year history of recurrent convulsions, which recently were accompanied by severe central abdominal pain radiating to the back, vomiting two to three times daily, and constipation. She experienced her first generalised convulsion at the age of 12. An interictal electroencephalogram (EEG) was normal and following a second generalised seizure 2 months later, she was started on sodium valproate $200 \mathrm{mg}$ twice daily. There was no past history of febrile or childhood seizures and she had not had absences or myoclonus. The seizures occurred with no aura and were not related to sleep cycles. Past medical and psychiatric histories were negative. Her father was well but two of his sisters had epilepsy and mother and brother were both well. She had no further seizures over the next 2 years. The epilepsy then deteriorated with between one and three seizures per year and over the next 3 years the dose of sodium valproate was gradually increased to $1400 \mathrm{mg}$ daily. A magnetic resonance imaging (MRI) scan of the brain was normal. Lamotrigine $50 \mathrm{mg}$ twice daily was added and following a further increase of lamotrigine to $50 \mathrm{mg}$ three times daily, the patient developed episodes of severe abdominal pain and vomiting and was referred to the Metabolic Clinic at King's College Hospital. At the same time a different type of seizure emerged, consisting of loss of consciousness without tonic-clonic movements. None of the episodes were observed during 5 days of videotelemetry and interictal records were normal.
When she was seen in the Metabolic Clinic she was having generalised seizures once a week. Her anti-epileptic medication at the time of referral was sodium valproate $1400 \mathrm{mg}$ and lamotrigine $50 \mathrm{mg}$. The patient's family history for porphyria was negative. There was no history of cigarette smoking or drug misuse and she did not drink any alcohol. The patient was in part-time education. On system enquiry she complained of disturbed sleep, weight loss of 2 stone over the past year, and chronic constipation that required enemas every 2 weeks. She also suffered from irregular periods. Physical and neurological examinations were unremarkable. Biochemistry showed urinary $\delta$-aminolaevulinic acid $70.9 \mu \mathrm{mol} / \mathrm{mmol}$ creatinine (reference range $<3.8$ ), urinary porphobilinogen $65.3 \mu \mathrm{mol} / \mathrm{mmol}$ creatinine (reference range $<1.5$ ), faecal porphrin $22 \mathrm{nmol} / \mathrm{g}$ (reference range $<46$ ), and erythrocyte hydroxymethylbilane synthase $18 \mathrm{nmol} / \mathrm{ml}$ red blood cells/hour (reference range 20-42). On the basis of the clinical history and the blood results (see table 1) a diagnosis of acute intermittent porphyria was established. Further analysis revealed a molecular defect in the hydroxymethylbilane synthase gene. Symptoms were severe enough to warrant several courses of haem arginate. Following the diagnosis of acute neuropsychiatric porphyria, sodium valproate was stopped and the patient was started on gabapentin $500 \mathrm{mg}$ three times daily. On this regime the patient's appetite improved, she was able to increase her weight by 1 stone, and had a bowel movement on alternate days. Unfortunately, the frequency of generalised tonic-clonic fits increased with up to 25 episodes in 3 months. The gabapentin was slowly titrated to $1000 \mathrm{mg}$ three times daily and clonazepam was introduced and slowly increased to $\mathrm{l} \mathrm{mg}$ twice daily. She is now experiencing about one seizure per year, some of which occur following acute attacks of porphyria. A prolonged sleep EEG showed normal background rhythms with bilateral bursts of beta activity, which were thought to be generalised epileptiform discharges. A high resolution MRI was normal. Over the last 2 years the patient experienced the occasional episode of abdominal

Abbreviations: $\mathrm{CT}$, computed tomography; $\mathrm{EEG}$, electroencephalogram; GABA, $\gamma$-aminobutyric acid; MRI, magnetic resonance imaging; PPOX, protoporphyrinogen oxidase 


\begin{tabular}{|c|c|c|c|c|c|c|c|}
\hline Patient & ALA & Urine PBG & Porphyrins & $\begin{array}{l}\text { Red cell } \\
\text { HMBS }\end{array}$ & $\begin{array}{l}\text { Plasma } \\
\text { fluorescense }\end{array}$ & $\begin{array}{l}\text { Faecal } \\
\text { porphyrins }\end{array}$ & Molecular defect \\
\hline 1 & 70.9 & 65.3 & 6500 & 18 & Negative & 22 & $\begin{array}{l}\text { HMBS: exon 12; } \\
\text { C.731 T>G, L } \\
244 R\end{array}$ \\
\hline 2 & 17 & 10.6 & 299 & 32 & Positive & 267 & $\begin{array}{l}\text { PPOX: exon 9; } \\
\text { C.884 T>C, L } \\
\text { 295P }\end{array}$ \\
\hline 3 & 25.8 & 28.3 & 420 & 37 & Positive & 120 & $\begin{array}{l}\text { PPOX: intron 5; } \\
\text { IVS5-(25-16) del } \\
\text { CTT AG TCCT }\end{array}$ \\
\hline $\begin{array}{l}\text { Reference } \\
\text { Range }\end{array}$ & $\begin{array}{l}<3.8 \\
\text { ( } \mu \mathrm{mol} / \mathrm{mmol} \\
\text { creatinine) }\end{array}$ & $\begin{array}{l}<1.5 \\
\text { (umol/mmol } \\
\text { creatinine) }\end{array}$ & $\begin{array}{l}<35 \\
\text { (nmol/mmol } \\
\text { creatinine) }\end{array}$ & $\begin{array}{l}20-42 \\
(\mathrm{nmol} / \mathrm{h} / \\
\mathrm{ml} / \mathrm{RBC})\end{array}$ & - & $\begin{array}{l}<46 \\
\text { (nmol/g } \\
\text { dry weight) }\end{array}$ & \\
\hline
\end{tabular}

pain, mainly pre-menstrual and examination stress related, not requiring haem arginate treatment. The patient is now in full-time education and did not have to take time off university over the last year. It was found that the porphyria was inherited through the maternal route.

\section{Case 2}

A 40 year old Caucasian female was referred to the Metabolic Clinic with a 3 year history of refractory epilepsy with hyponatraemia (119 mmol/L) and abnormal liver toxicity tests. The patient complained of two types of fits: generalised tonic-clonic seizures with prodromal headaches and incontinence at a frequency of one seizure every 2 weeks, and daily minor seizures. The latter consisted of violent movements of arms and legs during which she apparently became unconscious but regained consciousness relatively quickly. The patient had a past medical history of postoperative muscle weakness, which required intensive care unit treatment, and of depression, which was treated with a short course of thioridazine. She also suffers from bronchitis and asthma. A maternal uncle suffered from epilepsy. The patient was an unemployed machinist and smoked 15 cigarettes per day, drank alcohol in small amounts, but did not use illicit drugs. She was initially treated with carbamazepine, but because of hyponatraemia this was changed to phenytoin $200 \mathrm{mg}$ daily, which still did not control her seizures. A computed tomography (CT) brain scan was normal and the interictal EEG showed an abnormal background with a dominant rhythm of six cycles per second but no epileptiform discharges. With photic stimulation an episode of limb shaking occurred with no EEG change, which was thought to be a non-epileptic attack.

The patient was referred to the Metabolic Clinic at King's College Hospital. There was no family history of porphyria. She said that she had also suffered repeatedly from low back and left inguinal fossa pain with constipation requiring regular laxatives. She had nocturia with dark foul smelling urine and suffered from paraesthesiae in both hands. She also said that her skin was very sensitive to sunlight and that she had the occasional rash. Physical and neurological examinations were normal apart from scattered eczematous skin lesions. Biochemistry showed a urinary $\delta$-aminolaevulinic acid of $17.0 \mu \mathrm{mol} / \mathrm{mmol}$ creatinine (reference range $<3.8$ ), urinary porphobilinogen $10.6 \mu \mathrm{mol} / \mathrm{mmol}$ creatinine (reference range $<1.5$ ), total faecal porphyrins $267 \mathrm{mmol} / \mathrm{g}$ (reference range $<46$ ), and red cell hydroxymethylbilane synthase $32 \mathrm{nmol} / \mathrm{ml}$ red blood cells/hour (reference range 20-42). Plasma fluorescence scan was positive. On the basis of these results a diagnosis of variegate porphyria in clinical remission was established and this was confirmed by the demonstration of a protoporphyrinogen oxidase gene mutation. Phenytoin was withdrawn over 6 weeks and lamotrigine was started in a dose of $50 \mathrm{mg}$ twice daily. During this time the number of generalised seizures increased to approximately three fits per week but soon dropped to one seizure every 6 months, and during the same time her urinary porphyrin metabolites had returned to almost normal. She now suffers from tonic-clonic convulsions every 3-4 months and has the occasional episode of abdominal pain with constipation; however, this does not require hospital admission. Her health at the moment is satisfactory and her seizures seem to be much better controlled compared to when she was on phenytoin. The porphyria was found to be inherited through the maternal route.

\section{Case 3}

A 27 year old Caucasian female was referred to the Metabolic Clinic at King's College Hospital with an 18 year history of refractory epilepsy and an acute neurological illness with a concomitant episode of dark urine. The patient suffered from seizures since the age of 9 years. The first three seizures were generalised tonic-clonic fits. The attacks then changed to a shooting feeling of pins and needles through her body, mainly on the right side, which was occasionally accompanied by shaking and weakness of her right arm and/or leg. These attacks only lasted a few seconds; there was no loss of consciousness. Past medical and psychiatric histories were negative. There was no family history of epilepsy. The patient did not smoke cigarettes, drink alcohol, or use illicit drugs. She had finished a business degree, but was unable to find employment because of her chronic ill health. On telemetry there were epileptiform discharges during these sensory attacks. Over the last 3 years the patient also developed attacks of falling backwards rigidly without warning or was 'crumbling' to the ground without any attempt to save herself. She was partially aware of what was going on around her but felt cut off from her surroundings. She sustained numerous head injuries and two broken wrists. She would suffer two to three attacks per week. There was no consensus on the interpretation of the telemetry during these attacks and were initially thought to represent non-epileptic fits. When further seizures were witnessed by medical staff in hospital, there was little doubt that they were of epileptic origin and subsequent review of the EEGs showed a decrement of activity compatible with an ictal origin. Previous interictal recordings had persistently showed a moderately severe diffuse background abnormality, which remained unexplained. A MRI scan of the brain was normal. At this time the patient was treated with gabapentin $800 \mathrm{mg}$ three times daily and carbamazepine $800 \mathrm{mg}$ twice daily, but 
had previously been tried unsuccessfully on lamotrigine, primidone, sodium valproate, phenytoin, vigabatrin, and phenobarbitone.

The control of the seizures remained unsatisfactory and the patient underwent a trial of topiramate ( $175 \mathrm{mg}$ daily). Four months after starting this drug she was found collapsed on the floor with a right-sided weakness. Her consciousness level was reduced (Glasgow Coma Scale 10/15) and she needed to be ventilated. Investigations, including auto-antibody screen, lumbar puncture, CT brain, carotid Dopplers, serial high resolution MRI brain scan and diffusion weighted images, fluorodeoxyglucose positron emission tomography (FDG PET) scan, and angiography, all proved to be normal. A series of EEGs was performed. The original EEG showed bursts of frontal slow waves consistent with her consciousness level. As her consciousness level improved the background rhythms remained slow and frequent bursts of delta activity compatible with a metabolic encephalopathy were seen.

A few days after admission the patient's urine was noted to be dark. There was no family history of porphyria. Biochemistry revealed a urinary $\delta$-aminolaevulinic acid of $25.8 \mu \mathrm{mol} / \mathrm{mmol}$ creatinine (reference range $<3.8$ ), urinary porphobilinogen $28.3 \mu \mathrm{mol} / \mathrm{mmol}$ creatinine (reference range $<1.5$ ), faecal protoporphyrin $820 \mathrm{nmol} / \mathrm{g}$ (reference range $<134$ ), and red cell hydroxymethylbilane synthase $37 \mathrm{nmol} /$ $\mathrm{ml}$ red blood cells/hour (reference range 20-42). Plasma fluorescence scan was positive. A diagnosis of variegate porphyria was established and confirmed by the demonstration of a protoporphyrinogen oxidase gene mutation. Carbamazepine and topiramate were withdrawn, but the patient remained on gabapentin $900 \mathrm{mg}$ three times daily and clobazam $10 \mathrm{mg}$ at night on which her seizures seemed to be reasonably well controlled. She was treated with a course of haem arginate. Her general condition improved but she left with a major neurological deficit. After rehabilitation she was able to stand with support, but had a moderately severe asymmetric spastic quadriparesis, worse on the right side with spastic dysarthria and dysphagia but preserved cognition. The porphyria was found to be inherited through the paternal route.

\section{DISCUSSION}

Three patients have been referred to the Metabolic Clinic at King's College Hospital within 1 year with epilepsy as a presenting symptom and found to have one of the acute neuropsychiatric porphyrias. Two of the patients had variegate porphyria and one had acute intermittent porphyria. All give a similar history of longstanding poorly controlled epilepsy on one or more porphyrinogenic anticonvulsants - that is, sodium valproate, lamotrigine, carbamazepine, phenytoin, and topiramate. They were receiving large doses of the drugs and often more then one agent. None had a family history of porphyria. After many years of ill health they eventually developed signs or symptoms, which led to the diagnosis of porphyria. After treatment for their porphyria and changing their anticonvulsants to nonporphyrinogenic agents in two cases - that is, gabapentin and clonazepam - the porphyria went into both clinical and biochemical remission and the epilepsy considerably improved.

Both acute intermittent and variegate porphyria can produce a wide range of neurological symptoms. Early in the last century, Waldenström ${ }^{3}$ called the disease the little imitator in distinction to the more common manifestations of neurosyphilis. A predominantly axonal neuropathy, which can be acute and involve the bulbar cranial nerves and respiratory muscles, is well described. ${ }^{4}$ The severe constipation and episodes of abdominal pain, hypertension, and tachycardia seen during an acute attack of porphyria may be because of an autonomic neuropathy. Involvement of the central nervous system has been less well documented. Delirium and confusion can complicate an acute attack and psychiatric symptoms occur in as many as $50 \%$ of cases in the major published series. ${ }^{1}$ In a detailed review of the early literature and presentation of five more cases, Hierons ${ }^{5}$ found no consistent pathology that could explain these symptoms. Ischaemic abnormalities secondary to hypertension and ventilatory failure were described and reversible cortical lesions during an acute relapse have been reported on imaging and attributed to vasospasm. ${ }^{6}$ Central pontine myelinolysis due to rapid correction of hyponatraemia ${ }^{7}$ or other reversible imaging changes that remain unexplained have been described. ${ }^{8}$ One of the cases reported by Heirons ${ }^{5}$ developed a spastic quadraparesis and was found to have spinal cord demyelination at autopsy. Several mechanisms have been proposed to explain the neurological symptoms of the acute neuropsychiatric porphyrias. Overproduction of $\delta$-aminolaevulinic acid, porphobilinogen, or porphyrins may lead to their accumulation in nervous tissue exhibiting neurotoxic properties. ${ }^{9} \delta$-Aminolaevulinic acid has also been demonstrated to interfere with neurotransmitters of the central nervous system: at high concentrations inhibiting the uptake of $\gamma$-aminobutyric acid (GABA) and glutamate in rat cortical synaptosomes and at low concentration acting as an agonist at pre-synaptic GABA autoreceptors, thereby inhibiting the release of GABA from nerve endings. ${ }^{10}$ The interaction of $\delta$-aminolaevulinic acid with GABA and glutamate may be a possible explanation for the occurrence of seizures during acute porphyria attacks. Another major hypothesis is that deficiency of haem may lead to decreased levels of key haem proteins, such as tryptophan dioxygenase in the liver. This results in an increased supply of tryptophan to the brain, which in turn leads to elevated levels of the neurotransmitter serotonin that may contribute to psychiatric symptoms as well as the peripheral neuropathies of the acute porphyrias. ${ }^{11}$ Finally, $\delta$-aminolaevulinic acid has been implicated in the generation of free radicals that are involved in potentially tissue damaging processes such as lipid peroxidation. ${ }^{12}$

The relationship of seizures to porphyria is complex. Most common are acute symptomatic generalised seizures occurring in the context of acute intermittent porphyria in relapse. In major series this is said to occur in $10-20 \%$ of cases $^{1}$ but this may be because of over reporting. A postal survey of the Swedish National Porphyria Centre found that six out of 117 cases $(5.1 \%)$ with manifest acute intermittent porphyria (AIP) had experienced seizures at some time in their life. ${ }^{13}$ This has to be compared with the cumulative lifetime incidence of epilepsy in the general population, which is of the order of $3 \% .{ }^{14}$ Convulsive seizures may be the presenting symptom of an acute relapse $\mathrm{e}^{15}$ and the subsequent use of enzyme-inducing antiepileptic drugs can cause a worsening of the fits and new symptoms, such as an acute neuropathy. The first case presented here probably suffered from primary generalised epilepsy in addition to porphyria and thus had the chance association of two genetically determined diseases. Only $10 \%$ of carriers of the gene defect for porphyria manifest the disease and it is likely the addition of lamotrigine precipitated the porphyria and caused the worsening of her epilepsy. There are two other case reports of the probable chance association of porphyria and primary generalised epilepsy. ${ }^{16}{ }^{17}$ It is much less clear if porphyria can be the cause of chronic symptomatic partial or generalised epilepsy. The second case had late onset cryptogenic generalised epilepsy. Porphyria was diagnosed when she developed abnormal liver toxicity tests and hyponatraemia, which has been attributed to inappropriate secretion of antidiuretic hormone. ${ }^{18}$ Seizures improved when she was switched from 
phenytoin to lamotrigine. The EEG had shown a diffuse background abnormality of moderate severity raising the possibility of an ongoing encephalopathy that might have been an aetiological factor in the epilepsy. Case 3 had an unusual neurological illness. After generalised seizures in childhood, focal sensory seizures occurred with no structural lesion. As an adult she developed severe and frequent atonic seizures - a symptom more commonly seen in the epileptic encephalopathies of childhood. The EEG had been repeatedly noted to be diffusely slowed, which was unexplained but in retrospect may have had a metabolic cause. After treatment was started with topiramate a devastating neurological disease occurred with stroke-like onset, decreased level of consciousness, subsequent asymmetric spastic quadriparesis, and prominent brain stem signs. The final clinical picture would be in keeping with a monophasic acute demyelinating illness, but she repeatedly had normal imaging. 'Stroke-like' episodes have been said to occur with topiramate, ${ }^{19}$ but a disease of this severity has not been reported: topiramate has recently been classified as porphyrinogenic. While being cared for in the intensive care unit she was noted to have dark urine. After the occurrence of two rare and unusual neurological disorders it is less easy to ascribe the subsequent diagnosis of variegate porphyria to a chance association. If porphyria can cause chronic epilepsy it seems rare or is frequently undiagnosed. There are two paediatric cases reports of symptomatic generalised epilepsy with myoclonus, absences, cognitive impairment, and generalised spike and wave in the EEG who subsequently developed porphyria. ${ }^{20} 21$ The epilepsy started in infancy and a diagnosis of porphyria was made at the ages of 7 and 14 after many years of intractable seizures. As with our two cases no other aetiology for their neurological conditions was established.

In summary, the three cases demonstrate that in refractory epilepsy metabolic causes, such as neuropsychiatric, porphyria need to be considered, especially when the seizure frequency increases on high doses of anticonvulsants. Establishment of a meticulous past medical and psychiatric history is indispensable and porphyria specific questions, such as the enquiry about abdominal pains, severe constipation and vomiting, the colour of the urine and skin lesions need to be asked for. Once the diagnosis of porphyria related seizures is confirmed, treatment of the porphyria itself and the choice of non-porphyrinogenic anticonvulsants will most likely improve porphyria related seizures. Although seizures are a rare but well recognised feature of acute intermittent porphyria in clinical relapse there are few reports of porphyria in people with chronic epilepsy. It is possible that amongst patients with poorly controlled epilepsy, particularly those whose epilepsy deteriorates with treatment, there may be cases of neuropsychiatric porphyria not yet exhibiting florid signs but whose porphyria may nevertheless be contributing to the epilepsy.

\section{ACKNOWLEDGEMENTS}

We are grateful to Dr A Deacon and colleagues for the performance of the porphyria analyses, the Stone Foundation for financial support, and to Dr Guillof and Dr Harwood for referring two of the cases.

\section{Authors' affiliations}

A S Winkler, Regional Movement Disorders and Autonomic Unit, King's College Hospital, London, UK

T J Peters, Department of Clinical Biochemistry, King's College Hospital, London, UK

R D C Elwes, The Centre for Epilepsy, King's College Hospital, London, UK

Competing interests: none declared

\section{REFERENCES}

1 Crimlisk HL. The little imitator-porphyria: a neuropsychiatric disorder. J Neurol Neurosurg Psychiatry 1997;62:319-28.

2 Thadani H, Deacon A, Peters TJ. Diagnosis and management of porphyria. Brit Med J' 2000;320:1647-51.

3 Waldenström J. Studien über porphyrie. Acta Medica Scandinavia 1937;92(suppl): 1-24.

4 Windebank AJ, Bonkovlsky HL. Porphyric neuropathy. In: Dyck PJ, Thomas PK, Griffin JW, et al, eds. Peripheral neuropathy. Philadelphia: WB Saunders, 1993:1161-8.

5 Hierons R. Changes in the nervous system in acute porphyria. Brain 1957;80:176-92.

6 King PH, Bragdon AC. MRI reveals multiple reversible cerebral lesions in an attack of acute intermittent porphyria. Neurol 1991;41:1300-2.

7 Susa S, Daimon M, Morita Y, et al. Acute intermittent porphyria with central pontine myelinolysis and cortical laminar necrosis. Neuroradiology 1999;41:835-9.

$8 \mathrm{Utz} \mathrm{N}$, Kinkel B, Hedde JP, et al. MR imaging of acute intermittent porphyria mimicking reversible posterior leukoencephalopathy syndrome. Neuroradiology 2001:43:1059-62.

9 Pierach CA, Edwards PS. Neurotoxicity of delta-aminolevulinic acid and porphobilinogen. Exp Neurol 1978;62:810-4.

10 Brennan MJ, Cantrill RC. Delta-aminolaevulinic acid is a potent agonist for GABA autoreceptors. Nature 1979;280:514-5.

11 Litman DA, Correia MA. L-tryptophan: a common denominator of biochemical and neurological events of acute hepatic porphyria? Science 1983;222:1031-3.

12 Monteiro HP, Bechara EJ, Abdalla DS. Free radicals involvement in neurological porphyrias and lead poisoning. Mol Cell Biochem 1991;103:73-83.

13 Bylesjo I, Forsgren L, Lithner F, et al. Epidemiology and clinical characteristics of seizures in patients with acute intermittent porphyria. Epilepsia 1996;37:230-5.

14 Hauser WA, Kurland LT. The epidemiology of epilepsy in Rochester, Minnesota, 1935 through 1967. Epilepsia 1979;16:1-66.

15 Scane AC, Wight JP, Godwin-Austen RB. Acute intermittent porphyria presenting as epilepsy. Brit Med J 1986;292:946-7.

16 Magnussen R, Doherty JM, Hess RA, et al. Grand mal seizures and acute intermittent porphyria. Neurology 1975;25:121-5.

17 Suzuki A, Aso K, Ariyoshi C, et al. Acute intermittent porphyria and epilepsy; safety of clonazepam. Epilepsia 1992;33:108-11.

18 Ludwig D, Goldberg M. Hyponatraemia in acute intermittent porphyria resulting from secretion of antidiuretic hormone. Ann N Y Acad Sci 1963;104:710-34.

19 Stephen LU, Maxwell JE, Brodie MJ. Transient hemiparesis with topiramate. BMJ 1999; $318: 845$

20 Fifi AR. Acute intermittent porphyria and epilepsy. Arch Dis Child 1979:54:644-5.

21 Birchfield RI, Cowger ML. Acute intermittent porphyria with seizures. Am J Dis Child 1966;112:561-5. 